\title{
Correction to: Pre-compatible almost endomorphisms and semigroups whose cube is a band
}

\author{
R. A. R. Monzo ${ }^{1}$
}

Received: 6 September 2017 / Accepted: 18 September 2017 / Published online: 6 November 2017

(C) Springer Science+Business Media, LLC 2017

\section{Correction to: Semigroup Forum Vol. 67 (2003) 355-372 https://doi.org/10.1007/s00233-001-0004-y}

In the lattice of subvarieties of the variety $\mathcal{V}=[x y z=x y w y z]$ depicted in $\mathrm{p} .370$, the following inclusions are missing:

$$
\begin{aligned}
{[x y z} & =x w] \subset[x y z=x z], \\
{[x y z} & =w z] \subset[x y z=x z], \\
{[x y z} & =x y] \subset\left[x y z=x y w ; x^{3}=x^{2}\right], \\
{[x y z} & =y z] \subset\left[x y z=w y z ; x^{3}=x^{2}\right], \\
{[x y z} & \left.=x^{2}\right] \subset\left[x w y=x v y ; x^{3}=x^{2}\right], \\
\text { and } \quad[x y z & \left.=z^{2}\right] \subset\left[x w y=x v y ; x^{3}=x^{2}\right] .
\end{aligned}
$$

The complete diagram for the lattice is given in Fig. 1. None of the other results of the paper are affected by the missing inclusions.

Communicated by Mikhail Volkov.

The online version of the original article can be found under https://doi.org/10.1007/s00233-001-0004-y.

$\triangle$ R. A. R. Monzo

bobmonzo@talktalk.net

110 Albert Mansions, Crouch Hill, London N89RE, UK 


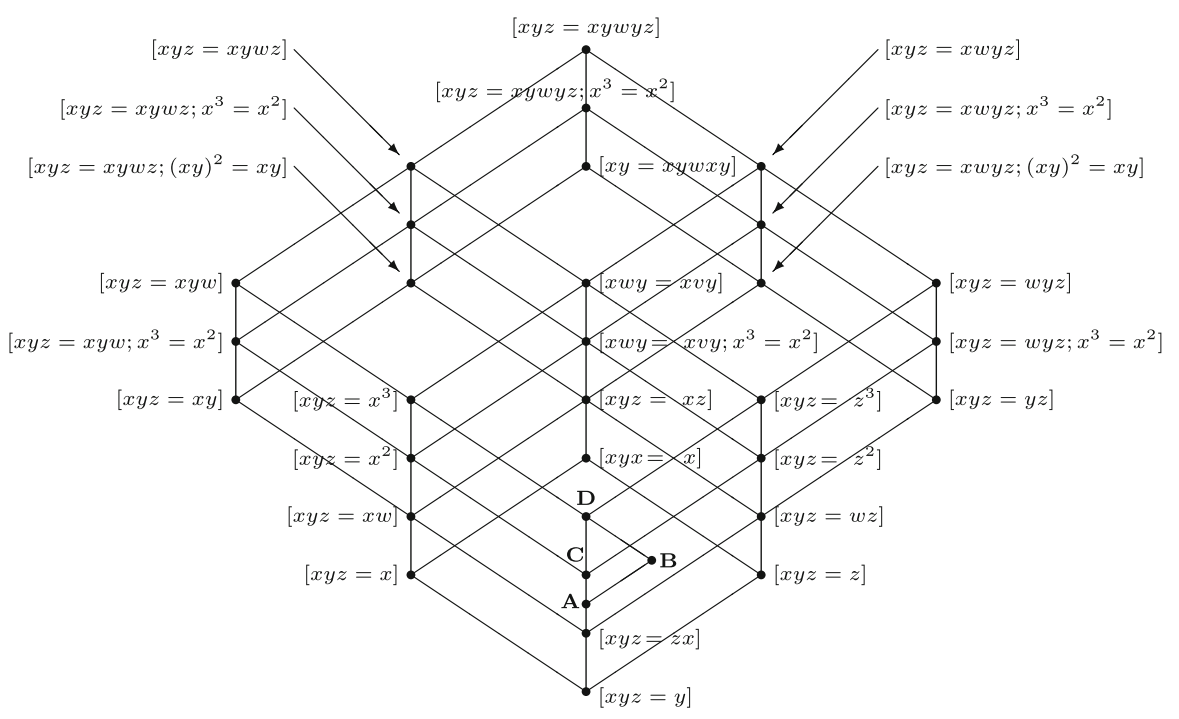

Fig. 1 The lattice of subvarieties of $\mathcal{V}$

Acknowledgements Thanks to Edmond W. H. Lee for pointing out the missing inclusions. 